RU Влияние индивидуальных особенностей использования мысленных образов на переводческие решения при переводе художественного текста (на материале эксперимента)

\author{
Шипулин А. Г.
}

Аннотация. Цель исследования - установление связи между индивидуальными особенностями использования мысленных образов при когнитивной обработке информации и результатами перевода художественного текста. В статье рассматривается природа мысленных образов и их роль в процессе создания текста перевода. Научная новизна работы состоит в том, что впервые проведено экспериментальное исследование влияния способности/склонности к построению разных видов мысленных образов на перевод художественного текста. Полученные результаты позволяют сделать заключение о наличии связи высокой силы между индивидуальной склонностью к использованию предметно-ситуативных образов при когнитивной обработке информации и вероятностью выбора адекватных переводческих решений.

\title{
Influence of Translator's Mental Imagery Abilities on Literary Translation (Experimental Study)
}

\author{
Shipulin A. G.
}

\begin{abstract}
The paper aims to reveal the influence of a translator's mental imagery abilities in cognitive processing of information on literary translation. The article considers mental images nature and identifies their role in the process of literary translation. Scientific originality of the research lies in the fact that the author for the first time provides an experimental study on the influence of a translator's mental imagery abilities on literary translation. The findings allow concluding that a translator's cognitive readiness to create thematicsituational images in cognitive processing of information significantly influences translation adequacy.
\end{abstract}

\section{Введение}

Актуальность темы исследования обусловлена необходимостью корректировки и конкретизации существующих представлений о формировании и функционировании мысленных образов в процессе перевода при помощи эмпирических методов исследования; междисциплинарным характером этой проблемы, требующим учета новых данных когнитивной науки и психологии речи; а также назревшей необходимостью в развитии процессуальной транслатологии, в центре которой находится понимающий и порождающий текст человек, через использование в том числе психолингвистических методов исследования. Поскольку через текст человек взаимодействует с действительностью, изучение сущности ментальных репрезентаций, включая мысленные образы, и их роли в обработке информации играет ключевую роль для понимания процесса перевода.

Задачи работы заключаются в следующем: 1) проанализировать актуальные теоретические подходы к процессу когнитивной обработки текстовой информации и роли мысленных образов в данном процессе; 2) изучить при помощи эмпирических методов влияние индивидуальных особенностей при построении мысленных образов на результаты перевода художественного текста.

Для решения задач в работе использовались следующие методы исследования: метод анализа и синтеза теоретического материала; метод сплошной выборки для сбора анализируемых данных; анкетирование, шкалирование; качественный и количественный анализ текстов переводов испытуемых.

В качестве теоретической базы для проведения исследования послужили положения отечественных и зарубежных учёных (А. Н. Леонтьева, А. А. Залевской, Л. Барсалоу, С. Тиркконен-Кондит, А. Рапосо и др.), раскрывающие различные подходы к изучению мысленных образов в когнитивной науке и в процессе перевода, 
в частности корпореальный и деятельностный психолингвистические подходы, теория языка и ситуативного моделирования Л. Барсалоу, а также концепция встречного моделирования в отечественной психолингвистике.

Практическая значимость исследования определяется возможностью использования полученных результатов и общих выводов для дальнейшего исследования роли мысленных образов в процессе перевода и для развития универсальной психолингвистической теории восприятия и производства текстов. Полученные данные могут найти применение в процессе учебно-методической деятельности при создании учебников, учебных пособий по переводоведению, психолингвистике и психологии речи.

\section{Современные представления о когнитивной обработке информации}

С конца прошлого века большое развитие получили концепции обработки информации, основывающиеся на корпореальном (телесном) подходе к познанию, согласно которым ментальные репрезентации основываются на телесном опыте человека. Так, например, установлено, что безусловно корпореальную основу имеет осознание человеком времени [3]. Корпореальный подход получил основательное нейронаучное обоснование; доказано, например, что нейронные субстраты перцептов и вторичных образов в значительной степени совпадают, то же касается реально выполняемых и мысленно представляемых действий; также имеются эмпирические подтверждения активации сенсомоторных отделов коры мозга при решении чисто интеллектуальных задач, в том числе связанных с пониманием речи [7]. Эти факты могут служить доводом в пользу предположения Л. Барсалоу о том, что понимание реализуется в результате перцептивного и моторного моделирования. Ментальные модели появляются как результат активации сенсомоторных участков коры головного мозга при отсутствии перцептивных стимулов и двигательных действий [5].

С точки зрения субъекта эти ментальные модели принимают форму перцептивных, моторных и интроспективных образов, помещенных в контекст определенных потенциально возможных ситуаций, и таким образом подготавливают субъект к ситуативно-обусловленной деятельности. Это сближает сомато-центрические модели когнитивных процессов с деятельностным подходом [2]. Например, при представлении категории «журнал» моделируемый образ журнала, вероятно, будет встроен в какую-либо окружающую ситуацию с лицами и объектами, которые могут присутствовать вместе с этим предметом, а также соответствующими действиями, событиями и психическими состояниями. Представление категории в релевантной ситуации способствует эффективному взаимодействию с предметом.

В случае восприятия вербальной информации место мультимодальной перцептивной информации занимает текст, содержащий эту информацию. В связи с этим образы, возникающие при восприятии текста, можно в значительной степени рассматривать аналогично перцептам при восприятии действительности. Ряд исследований показывает, что при предъявлении отдельных лексических единиц, фраз и связных текстов, описывающих различные действия, у реципиента происходит активация сенсомоторной области коры головного мозга сходным образом, как если бы он наблюдал или осуществлял эти действия в реальности [10; 12]. Например, если герой рассказа открывает дверь, у читателя активируется те же моторные и зрительные области коры, которые задействуются при реальном выполнении этого действия.

\section{Роль построения ментальных образов в процессе перевода}

Теоретики и практики перевода также не раз отмечали роль мысленных образов как для процессов понимания исходного сообщения, так и в целях избежания межъязыковой интерференции при создании переводного текста. Большой вклад в теоретическое обоснование этого дидактического подхода внесла интерпретативная теория перевода, предложенная французскими переводоведами Д. Селескович и М. Ледерер. В противовес господствовавшим в то время пропозициональным взглядам на мышление, Д. Селескович (1968) разработала теорию смысла (théorie du sens), которую успешно применяла в преподавании устного перевода [11].

Д. Селескович исходит из того факта, что при вербальной коммуникации говорящие как правило не запоминают языковую форму высказанных мыслей, а сохраняют в памяти лишь выраженный смысл. Отсюда задача переводчика состоит в передаче на другой язык смысла переводимого высказывания. Смысл при этом определяется как невербальная ментальная репрезентация, возникающая в сознании переводчика как результат взаимодействия языкового содержания высказывания с экстралингвистической информацией. Согласно Д. Селескович, извлечение смысла происходит мгновенно и интуитивно, и лишь этот извлеченный смысл передаётся затем в переводе. Обращение к языковому содержанию, к значениям языковых единиц оригинала только затрудняет создание переводного текста.

Первоначально многообещающая теория интерпретативного перевода, однако, не получила должного систематического развития и эмпирического подтверждения своих исходных посылок. Несмотря на успешное применение в дидактике перевода, теория грешит идеализированным взглядом на процесс перевода, постулируя чёткое разделение двух языков в сознании переводчика. Существуют, однако, сильные аргументы и экспериментальные данные в пользу того, что при порождении речи на одном из языков в сознании билингвов, даже достаточно компетентных, какими являются переводчики, активируются оба языка [8]. Ряд переводоведов также указывают на то, что переводчики в первую очередь склонны рассматривать формальные соответствия 
и прибегают к другим методам только при неудовлетворительном результате буквального перевода. Как установила С. Тиркконен-Кондит [14], лингвистические структуры оригинального текста оказывают влияние не только на новичков, но и на профессиональных переводчиков. С большой вероятностью при переводе смысл не обособляется полностью от языковой формы, и девербализация, таким образом, не является непременным условием для создания текста перевода.

\section{Взаимодействие вербальных и модальных систем когнитивной обработки информации в процессе перевода}

Особенно значимыми для исследования процесса перевода представляются двусистемные концепции обработки информации, среди которых, как наиболее теоретически и экспериментально обоснованную, следует отметить теорию языка и ситуативного моделирования (Language and Situated Simulation Theory). Согласно данной теории, в процессе когнитивной обработки информации задействованы системы двух видов - языковые и модальные. Языковые системы включают в себя образы языковых форм. Модальные - создают динамические модели, конструирующие в мультимодальной форме содержание высказывания или текста.

При обработке текстовой информации в первую очередь активируются ассоциативные интер- и интралингвистические связи (на основе фонетических, таксономических признаков, лексической частотности и пр.), и лишь затем, если обнаруженная в этой системе информация оказывается несоответствующей выполняемой задаче, происходит ситуативное моделирование при помощи модально-специфических церебральных систем. Ситуативные модели в свою очередь вновь активируют языковые формы, и, таким образом, оба типа когнитивных систем взаимодействуют и циклично сменяют друг друга в процессе интерпретации текста [4].

Теория языка и ситуативного моделирования также имеет много общих моментов с разрабатываемой в отечественной психолингвистике теорией идентификации слова как «встречного моделирования»: «...языковые знания направляют встречное моделирование ситуаций и их составляющих, признаков последних и т.д., а те, в свою очередь, подкрепляют или заставляют уточнить вовлекаемые языковые знания» [1, с. 63].

До сих пор лишь немногие исследователи пытались эмпирически изучить роль сознательного или бессознательного построения мысленных образов в переводе; также количество участников в подобных исследованиях часто не превышает нескольких человек (см., например, [9]). Несомненно, это связано в том числе с трудностью организации эксперимента и интерпретации результатов, так как ментальные образы недоступны для внешнего наблюдателя, и, следовательно, судить о верности теоретических представлений возможно лишь постольку, поскольку они согласуются с косвенными эмпирическими данными, полученными методами интроспекции, опроса, анализа текстов и пр.

\section{Описание эксперимента}

Для определения профилей образной и вербальной обработки информации и их возможной связи со стратегиями, используемыми при переводе художественных текстов, мы провели эксперимент с участием студентов 4 курса факультета иностранных языков Брянского госуниверситета, обучающихся переводу.

Мы исходим из предположения, что сам факт того, что формальные межъязыковые соответствия не согласуется с целостным образом действительности, описываемой в тексте, будет с большей вероятностью отмечен теми переводчиками, которые проявляют сравнительно большие способности и/или склонности к когнитивной обработке информации при помощи мысленных образов. Соответственно, осознание неадекватности наиболее частотного формального соответствия интегративному образу ситуации будет инициировать поиск других, более подходящих вариантов перевода, что должно найти отражение в переводном тексте.

В данной статье мы рассмотрим только часть результатов, полученных на основе анализа данных эксперимента с участием 20 студентов 4 курса. Для всех русский язык является родным, а английский - первым иностранным.

Для анализа используются следующие данные:

1. Анкетирование на основе опросника объектного, пространственного воображения и вербальных способностей М. Кожевниковой и О. Блаженковой (Object-Spatial Imagery and Verbal Questionnaire) [6]. Опросник включает в себя три субшкалы по 15 утверждений каждая. Утверждения, относящиеся к разным субшкалам, даны вперемешку. Две субшкалы соотносятся с образным мышлением, и одна - с обработкой вербальной информации. Испытуемым требуется оценить по пятибалльной шкале, насколько каждое утверждение соответствует его способностям и склонностям - от 1 (совершенно не соответствует) до 5 (полностью соответствует). Окончательная оценка по каждой субшкале - это среднее значение ответов по 15 пунктам. Субшкала «Объектное воображение» позволяет оценить способность строить яркие и детализированные мысленные образы не только предметов, но и сцен, ситуаций. Поэтому иначе данную субшкалу можно было бы озаглавить как «предметноситуативное воображение». (Пример утверждения из данной субшкалы: Закрыв глаза, я могу легко представить себе сцену, которую пережил(а).) Подраздел «Пространственное воображение» оценивает способность к когнитивной обработке местоположения предметов, их движения и преобразования при помощи более абстрактных и схематичных мысленных образов. Третья субшкала измеряет использование вербальных стратегий. 
Анкетирование проходило в очной форме по индивидуальной карточке-опроснику.

2. Тексты перевода отрывка объемом 2630 знаков из первой главы книги Флоры Томсон “Still Glides the Stream" (от “The Oxfordshire village of Restharrow... is a long, straggling place...” до “...one of the sights of the village” [13, p. 2-4]. На данном этапе исследования нами был проанализирован перевод десяти фрагментов текста, имеющих весьма частые формальные соответствия в русском языке, значения которых, однако, с большой вероятностью не могут быть согласованы с целостной моделью действительности, изображаемой переводным текстом. Семь фрагментов представляют собой отдельные слова или словосочетания: honeysucklecovered porch (заросшая жимолостью веранда), gable end (фронтон, торец с фронтоном), redeemed from ugliness (спасаемые от уродства), а feature of the district (характерная черта этой местности, «изюминка»), with light switches in their hands (с фонариками в руках), dilly dilly (ути-утu), flock of ducks (утиная стая); в трех случаях с точки зрения логичности и непротиворечивости оценивался перевод сложных предложений.

Переводные тексты испытуемых сравнивались с сформированным нами «эталоном». Под «эталоном» в данном случае понимается перевод, в котором 100\% рассматриваемых фрагментов переданы логично и непротиворечиво по отношению друг к другу и остальному тексту. При этом для признания фрагмента соответствующим «эталону» не требовалось обязательное добуквенное совпадение фрагментов, а только их смысловое соответствие.

Для проверки взаимосвязи способности/склонности к построению разных видов мысленных образов (предметно-ситуативного и пространственного воображения и относительным числом удовлетворительно переведённых фрагментов из числа отобранных) для исследования был использован коэффициент линейной корреляции Пирсона. В результате для предметно-ситуативного воображения был получен коэффициент, равный 0,81 . Количественное выражение статистической зависимости даётся на основе шкалы Чеддока: полученный результат свидетельствует в пользу наличия высокой силы связи между рассматриваемыми переменными. Ниже приведено корреляционное поле данных с линией тренда (см. Рис. 1).

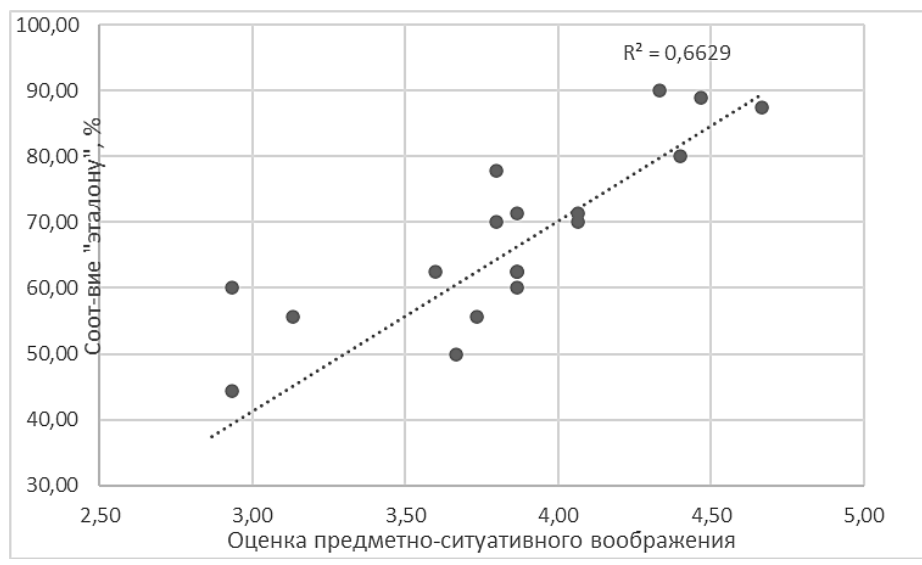

Рисунок 1. Корреляционное поле данных с линией тренда

Для пространственного воображения наличие существенной связи с выбором переводных соответствий на данном этапе исследования не установлено (коэффициент линейной корреляции - 0,18). Это может быть свидетельством того, что анализируемые части перевода не включали значительного количества элементов, требующих применения соответствующих когнитивных способностей.

Влияние вербальных способностей на результат перевода в данном исследовании также не установлено (коэффициент линейной корреляции - 0,10). Надо, однако, отметить, что мы не оценивали полученные варианты с точки зрения их благозвучности, ритмики, повторяемости лексических единиц и подобных вербальных характеристик.

\section{Заключение}

Таким образом, проведенный нами анализ вместе с вышеизложенными теоретическими предпосылками и данными когнитивной науки позволяет сделать следующие выводы.

Психолингвистическая теория переводческой деятельности непременно должна основываться на современных представлениях о сложном взаимодействии вербальных и модальных когнитивных систем обработки текстовой информации; корпореальные, динамические модели ментальных образов способны стать основой для новых перспективных направлений в изучении процесса перевода.

Проведенное нами исследование позволяет предположить наличие связи высокой силы между индивидуальной склонностью к использованию предметно-ситуативных образов при когнитивной обработке информации и вероятностью выбора адекватных переводческих решений при переводе художественного текста.

Отметим, что использованный нами опросник по своей сути дает возможность оценить склонность только к осознанному использованию тех или иных мысленных образов, однако, как показывают результаты, по крайней мере для начинающих переводчиков именно построение осознанных мысленных образов играет значительную роль. 
Перспективы дальнейшего исследования видятся нам в расширении базы исследования за счёт увеличения количества участников и числа анализируемых параметров с целью уточнения полученных результатов и выявления возможного влияния на процесс перевода иных типов когнитивных предпочтений и способностей.

\section{Источники | References}

1. Залевская А. А. Интерфейсная теория значения слова: психолингвистический подход. Лондон: IASHE, 2014. $180 \mathrm{c}$.

2. Леонтьев А. Н. Философия психологии. М.: Издательство Московского университета, 1994. 228 с.

3. Чугунова С. А. Время в языке и сознании: сомато-центрический подход // Вестник Брянского государственного университета. 2014. № 2. С. 415-419.

4. Barsalou L. W. Grounded cognition // Annual Review of Psychology. 2008. Vol. 59. P. 617-645.

5. Barsalou L. W. Perceptual symbol systems // Behavioral and Brain Sciences. 1999. Vol. 22. P. 577-660.

6. Blazhenkova O., Kozhevnikov M. The New Object-Spatial-Verbal Cognitive Style Model: Theory and Measurement // Applied Cognitive Psychology. 2008. № 23. P. 638-663.

7. Kosslyn S. M. Mental imagery and implicit memory // Markman K. D., Klein W. M. P., Suhr Julie. A. Handbook of Imagination and Mental Simulation. N. Y.: Psychology Press, 2009. P. 35-51.

8. Kroll J. F. Language selection in bilingual speech: Evidence for inhibitory processes // Acta Psychologica. 2008. Vol. 128. P. 416-430.

9. Martín de León C. Mental imagery in translation processes // Hermes - Journal of Language and Communication in Business. 2017. Vol. 56. P. 201-220.

10. Raposo A. et al. Modulation of Motor and Premotor Cortices by Actions, Action Words and Action Sentences // Neuropsychologia. 2009. Vol. 47 (2). P. 388-396.

11. Seleskovitch D. Pédagogie raisonnée de l'interprétation. P.: Didier érudition, 2002. 388 p.

12. Speer N. K. et al. Reading Stories Activates Neural Representations of Visual and Motor Experiences // Psychological Science. 2009. Vol. 20 (8). P. 989-999.

13. Thompson F. Still Glides the Stream. L.: Oxford University Press, 1966. 233 p.

14. Tirkkonen-Condit S. The monitor model revisited: Evidence from process research // Meta. 2005. Vol. 50 (2). P. 405-414.

\section{Информация об авторах | Author information}

RU Шипулин Алексей Григорьевич ${ }^{1}$

${ }^{1}$ Брянский государственный университет имени академика И. Г. Петровского

EN Shipulin Aleksey Grigorevich ${ }^{1}$

${ }^{1}$ Bryansk State Academician I. G. Petrovski University

${ }^{1}$ hi_upsilon@mail.ru

\section{Информация о статье | About this article}

Дата поступления рукописи (received): 09.06.2021; опубликовано (published): 30.07.2021.

Ключевые слова (keywords): корпореальный подход к познанию; мысленный образ; когнитивная обработка при переводе; ситуативное моделирование; шкалирование; corporeal approach to cognition; mental image; cognitive processes in translation; situational modelling; scaling. 